\title{
Progresso: desenvolvimento participativo e compartilhado
}

\author{
Progress: participatory and shared development \\ Progreso: desarrollo participativo y compartido
}

Recebido: 16/11/2021 | Revisado: 21/11/2021 | Aceito: 22/11/2021 | Publicado: 03/12/2021

\author{
Odirlei Arcangelo Lovo \\ ORCID: https://orcid.org/0000-0003-0576-9284 \\ Universidade Federal de Rondônia, Brasil \\ E-mail: oalovo@gmail.com
}

\begin{abstract}
Resumo
O ser humano se des-envolve à obra de Deus, por intermédio da ciência, da presença e da potência de pessoa, esses elementos predizem o Espírito de amor com o qual o ser humano administra a obra de Deus. A esponsalidade com o Criador é elemento fundante do agir humano, sob este prospecto se apresenta que a partilha precede o ter e, que a ciência é apresentar-se a realizar o reino. A ciência, a presença e a potência da pessoa, fruto de amor que acontece na relação de respeito à Criação. A proposta de narrar o ser humano administrador e cocriador, tem por base os documentos que compõem o Pensamento Social da Igreja e os documentos que elucidam a vida e vivência da família 'moral familiar'. O conhecimento não propulsa submissores e submissos, o conhecimento nos eleva à plenitude da vida humana de acordo com a capacidade de cada pessoa em administrar a obra de Deus.
\end{abstract}

Palavras-chave: Administrador; Essência administrativa; Parentalidade; Economicidade; Sociabilidade.

\begin{abstract}
The human being becomes involved in the work of God, through science, the presence and the power of each person, in this sense, these elements predict the spirit of love with which the human being is ready to administer the work of God . Liability to the Creator is a founding element of human action, under this prospect it is shown that sharing precedes having and that science is presenting itself to God to realize the kingdom. The person's science, presence and power will always be the fruit of love that happens in the relationship of respect for God's creation. The proposal to narrate the human being, administrator and co-creator of the work of God, is based on the documents of the social doctrine of the Church and the documents that elucidate the life and experience of the family 'family morals'. Knowledge, human science, is not done so that there are submissives and submissives, but, so that there is the fullness of human life according to the human capacity to manage the work of God.
\end{abstract}

Keywords: Administrator; Administrative essence; Parenting; Economics; Sociability.

\section{Resumen}

El ser humano se desarrolla en la obra de Dios, a través de la ciencia, la presencia y el poder de la persona, estos elementos presagian el Espíritu de amor con el que el ser humano administra la obra de Dios. La relación conyugal con el Creador es un elemento fundamental de la acción humana, bajo esta perspectiva se presenta que el compartir precede al tener y que la ciencia se está presentando para realizar el reino. La ciencia, la presencia y el poder de la persona es el resultado del amor que se da en la relación de respeto a la Creación. La propuesta de narrar al ser humano, administrador y cocreador, se basa en los documentos que componen el Pensamiento Social de la Iglesia y los documentos que dilucidan la vida y experiencia de la familia 'moral familiar'. El conocimiento no impulsa a sumisos y sumisos, el conocimiento nos eleva a la plenitud de la vida humana según la capacidad de cada persona para gestionar la obra de Dios.

Palabras clave: Administrador; Esencia administrativa; Parenting; Economía; Sociabilidad.

\section{Introduçãa}

O progresso do ser humano promove o avanço da ciência e da técnica e o conduz a prover o desenvolvimento participativo e compartilhado. Implica dizer que não se está falando na separação das pessoas em termos de classes, mas que cada pessoa é, segundo os próprios dons, chamada a compreender e a desenvolver-se, enquanto se envolve ao Reino de Deus. Quando a pessoa, se envolve no progresso participativo e compartilhado, diz com o Criador "Façamos o ser humano como nossa imagem e semelhança" (Gênesis, 1,26).

Envolver-se à obra de Deus é promover a presença, a ciência, e a potência humana, pessoa criada à imagem e 
semelhança de Deus. O ser humano cocria em esponsalidade com o Criador, isto é, em atitudes de amor. Neste sentido, a partilha precede o ter, o amor é vida, é edificar-se no Reino de Deus enquanto se administra e cocria a Criação.

Toda família, parentalidade, é convidada a administrar as necessidades, as possibilidades e os subsídios, de forma que não se reduzam ao familismo, mas que, se tornem a unidade primeira da família humana. Deste modo, é notório que a centralidade é a pessoa e não os sistemas de controles econômicos, social e parental.

Um sistema de controle econômico, por exemplo, pode anular a economicidade da pessoa, impedi-la de administrar a obra de Deus, por isso é necessário formar a consciência de pessoa, na afirmativa de que o ser humano é o administrador e cocriador da obra de Deus. O trabalho edifica a pessoa no sentido de que possa ajudar o ser humano a se cada vez mais humano.

\section{Metodologia}

O planejamento da pesquisa, os esquemas de resolução dos problemas e a objetivação das hipóteses permitiram aos pesquisadores aproximarem-se dos objetivos e, com isso, a pesquisa fomenta narrativas verificáveis. A pesquisa foi desenvolvida sobre afirmativas administrativas e teológicas e enquanto 'pano de fundo' fomenta-se a parentalidade, a economicidade e a sociabilidade humana.

É afirmativa a associação e inter-relação, enquanto metodologia, entre Teologia e Administração, de modo que, realizar a vontade de Deus - esponsalidade - significa administrar a criação e, por isso, há práxis teológica e, à medida que se faz teologia, compreende-se como administrar a Criação e, neste sentido, subentende-se que "a vida que Deus oferece ao homem, é um dom, pelo qual Deus participa algo de Si mesmo à sua criatura" (João Paulo II, 1995, n 34).

Eis que "Iahweh Deus tomou o homem e o colocou no jardim de Éden para o cultivar e o guardar" (Gênesis, 2,15). Sendo dever do ser humano cultivar o jardim, insere-se o momento posterior, a necessidade de administrar e cocriar. Administrar e dar significado, sentido e possibilidades ao que existe, avançando sobre o que não é possibilitado, mas que se alça em ser possibilitado, no futuro, pela ação humana, mediante a essência administrativa.

O humano sempre se des-envolve, mediante a essência administrativa e se torna ato administrativo de Deus na criação. Enseja-se que a esperança é constitutiva da ação necessária em perspectiva do reino esperançado, é preciso compreender que "a interpretação correta do conceito de ser humano como senhor do universo é entendê-lo no sentido de administrador responsável" (Francisco, 2018, n 116).

Diante do que se apresenta em epígrafe, procurou-se a elucidação de questões que estão relacionadas ao ser humano, vertendo-se a compreendê-lo como administrador da obra de Deus. Mediante os procedimentos metodológicos, conduziu-se às possibilidades, às interpretações e às informações, na afirmativa que "uma narrativa é composta por uma sequência singular de eventos, estados mentais, ocorrências envolvendo seres humanos como personagens ou autores" (Bruner, 2002, p. 46).

A narrativa tem por finalidade explorar, aprofundar e dar respostas às particularidades, onde a realidade não pode, ou não deve ser quantificada, particularizando ainda que, "Uma verdadeira pesquisa narrativa é um processo dinâmico de viver e contar histórias, e reviver e recontar histórias" (Clandinin \& Conelly, 2011, p. 18).

\section{Resultados e Discussão}

Para explorar o universo dos significados, das aspirações, das crenças, dos valores e práxis humana, utilizou-se, para a narrativa, dois núcleos fundamentais de dados, textos e informações, a saber: os documentos que constituem a (DSI) Doutrina (Pensamento) Social da Igreja; e os documentos que elucidam o projeto, a vivência e a dinâmica familiar, segundo a igreja católica. O uso desses dois núcleos tem por base, sua universalidade, isto é, são documentos que se destinam a toda a humanidade, diante dos dons de cada pessoa. 
Cada um dos itens da pesquisa foi desenvolvido, tendo por base os textos/documentos apresentados. Como pontos de discernimento, pesquisou-se fontes/obras para dar às narrativas, sentido de diálogo, com fundamentações de teólogos que não estão inseridos nos dois núcleos apresentados. As obras foram escolhidas pelo próprio pesquisador, tendo como critério a afinidade com o texto, sendo este o critério metodológico para sua escolha.

\subsection{Envolvimento e ciências à Criação}

A ciência humana, quando é fruto de esponsalidade com o Criador, é sinal que apresentam o caminhar humano, enquanto descoberta de si é um desafio que impele o humano a harmonizar os valores permanentes e a presença de Deus, com as novas descobertas. Quando as possibilidades de uns significam a ausência de subsídios às necessidades de outros, não se está falando de desenvolvimento participativo e compartilhado, que se faz pelas mãos humanas, sob a base da doação original das coisas por parte de Deus.

Nesse sentido, a pobreza é toda situação, que provoca humilhação à pessoa. Os seres humanos vivem entre angústias e esperanças, marcados por sua própria atividade, onde "cada trabalhador, [...], é a mão de Cristo que continua a criar e a fazer o bem" (João Paulo II, 2004, n 265). A vida humana se desenvolve, tendo por base os dons e os subsídios à disposição para realizar-se, mas, também, existe sua responsabilidade para com as gerações passadas, presentes e futuras.

Entende-se que, no desenvolvimento participativo e compartilhado, busca-se desenvolver o humano em sua totalidade, tanto na participação, mediante os dons recebidos, quanto no compartilhar a vida e vivência no reino em desenvolvimento. O ser humano é, desde o princípio, o significador da criação no mandado "cultivar e guardar a criação" (Gênesis, 1,15) em um movimento que se torna concomitante ao mandado de "sede fecundos, multipliquem-se e submeta a terra" (Gênesis, 1,28).

Terra é, então, o espaço da criação a ser desenvolvida pelo ser humano, e é o céu/reino, quando o humano age em esponsalidade com o Criador. Assim, o ser humano avança diante de sua própria contingência na proliferação das possibilidades, atendendo ao chamado de Deus para significar a criação/terra.

Entre angústias e esperanças, o ser humano deve promover a alteridade e o desenvolvimento participativo e compartilhado, na obra em desenvolvimento, sempre sob a perspectiva de que "Deus deu a terra a todo o gênero humano, para que ela sustente todos os seus membros, sem excluir nem privilegiar ninguém" (Francisco, 2018, n 93).

A práxis de amor promove o ser humano à solicitude de um cocriador e administrador, que tem a capacidade de perceber a dignidade da pessoa desde a concepção, reconhecendo o sentido e significado de si mesmo, enquanto imagem e semelhança de Deus, e descobrindo aos passos de fé que "Deus acode com sua graça inclusive onde não se lhe levanta propriamente um altar" (Rahner, 1969, p. 252).

A essência administrativa é o Dom primeiro, que possibilita o ser humano viver a dignidade de pessoa, é o próprio $\mathrm{Si}$ de Deus que habita o íntimo humano. A Graça precede o Dom, é enfático afirmar que a essência administrativa é o Dom primeiro que possibilita toda pessoa a exercitar-se, enquanto imagem e semelhança do Criador, para que possa compreender o Reino esperançado por Deus.

Cada pessoa deve estar em esponsalidade com o Criador, isso possibilita seu despertar para a essência administrativa, e compreender as necessidades, as possibilidades e os subsídios e, "nesta compreensão e amizade mútuas, nesta comunhão sagrada, devemos começar também a trabalhar juntos para construir o futuro comum da humanidade" (Paulo VI, 1967, n 43).

A sociabilidade é um processo, que diz respeito à capacidade associativa humana. A conjugalidade avança em prol da unidualidade do casal humano, possibilita relações unitivas e procriativas, diante de um processo onde a economicidade representa a atitude solícita do ser humano, reflexo do amor de Deus. Assim, "o homem deve encontrar o homem, as nações devem encontrar-se como irmãos e irmãs, como alhos de Deus” (Paulo VI, 1967, nº 43). 
Promover a cultura do encontro é dever de cada pessoa, é necessário que se possa ver e compartilhar a alegria de sentir-se que é carne da mesma carne e ossos dos mesmos ossos. O ser humano torna visível sua semelhança com o Criador, quando como criatura se pode perceber que em "cada trabalhador, [...], é a mão de Cristo que continua a criar e a fazer o bem" (João Paulo II, 2004, nº 265).

\subsection{A partilha precede o ter}

No desenvolvimento participativo e compartilhado, a partilha precede o ter, o desenvolvimento não tem vida própria, representa o interesse comum das pessoas e é verdadeira fonte de recursos sob a perspectiva da família humana: "por isso, sugeríamos a busca de meios de organização e de cooperação, concretos e práticos, para pôr em comum os recursos disponíveis e realizar, assim, uma verdadeira comunhão entre todas as nações” (Paulo VI, 1967, nº 43).

Esse é um processo pelo qual, diante da essência administrativa o humano vai se compreendendo enquanto humano húmus da terra, o homo ad-minister. Quando matrimônio e patrimônio, enquanto projetos de parentalidade se comunicam eficientemente com a vida e a vivência socioeconômica de todas as pessoas, se vê o desenvolvimento de todo humano e do humano todo. Paulo VI (1965) preconiza que:

O desenvolvimento econômico deve permanecer sob a direção do homem; nem se deve deixar entregue só ao arbítrio de alguns poucos indivíduos ou grupos economicamente mais fortes ou só da comunidade política ou de algumas nações mais poderosas. Pelo contrário, é necessário que, em todos os níveis, tenha parte na sua direção o maior número possível de homens, ou todas as nações, se se trata de relações internacionais. (Paulo VI, 1965, nº 65).

Isso, mais do que um ser humano que faz segundo os desígnios de Deus, é o ser humano que sabe qual é o seu lugar na criação, de modo que ser criatura ungida, não é preocupar-se só com a velocidade das ações, mas com a direção; “de igual modo, é necessário que as iniciativas dos indivíduos e das associações livres sejam coordenadas e organizadas harmonicamente com a atividade dos poderes públicos" (Paulo VI, 1965, n 65).

Sanches preconiza que "É, pois, fundamental reconhecer que não é apenas o sentido da vida que influencia qual existência a pessoa vai ter, pois sua posição socioeconômica modifica o sentido de sua existência" (Sanches, 2013, p. 42). Neste sentido, toda pessoa, é "em razão da sua vocação particular, têm o dever específico de interpretar à luz de Cristo a história deste mundo, enquanto são chamados a iluminar e dirigir as realidades temporais, segundo o desígnio de Deus Criador e Redentor" (João Paulo II, 1981, nº 5).

A pessoa deve ser observada sob seu contexto de vida, "Se for totalmente livre, negará as condições históricas do humano: se for totalmente determinado, sufocará uma de suas características básicas: a liberdade” (Sanches, 2013, Pág. 42).

Chamado a iluminar e a dirigir, diante da essência administrativa, pode-se compreender que se é, em família, convidado a administrar e cocriar o mundo em esponsalidade com o Criador. Não é o caso de encontrar a substância do ser, mas o ser desta, que é a substância humana, indicando que há um distanciamento entre a consciência de si e o si da consciência.

Nesse sentido, o verdadeiro desenvolvimento se faz sob o projeto de Deus, e isso implica que se tenha, primeiramente, consciência de que o ser social estimula uma liberdade social, "Enfim, a pessoa humana é livre, mas não tão livre a ponto de ser algo diverso de si mesma, ou seja, sua liberdade se dá na ordem do ser e é condicionada por ela” (Sanches, 2013, Pág. 41).

Quando se enfatiza que o matrimônio e o patrimônio devem ser pensados enquanto unidade primeira da família humana, sob um sentido de sacramentalização da vida e vivência humana, está se propondo um pensamento profundo, onde se ouve que "Igreja pode ser guiada para uma intelecção mais profunda do inexaurível mistério do matrimônio e da família a partir das situações, perguntas, ansiedades e esperanças dos jovens, dos esposos e dos pais de hoje” (João Paulo II, 1981, nº 4). 
É preciso despertar o humano para a sua humanidade e agir na perceptiva do Reino. Não há dúvida que a humanidade está em desequilíbrio quanto à posse, uso e poder, na busca responsável pela edificação da vida humana é de se afirmar que,

Se é verdade que o mundo sofre por falta de convicções, nós convocamos os pensadores e os sábios, católicos, cristãos, os que honram a Deus, os que estão sedentos de absoluto, de justiça e de verdade: todos os homens de boa vontade. Seguindo o exemplo de Cristo, ousamos pedir-vos instantemente: "buscai e encontrareis", abri os caminhos que levam pelo auxílio mútuo a um aprofundamento do saber, a ter um coração grande, a uma vida mais fraterna numa comunidade humana verdadeiramente universal. (Paulo VI, 1967, $\mathrm{n}^{\circ}$ 85).

Eis que Francisco (2016) apresenta que, "na vida familiar, não pode reinar a lógica do domínio de uns sobre os outros, nem a competição para ver quem é mais inteligente ou poderoso, porque esta lógica acaba com o amor" (Francisco, 2016, n 98). Por esta visão, percebe-se que a essência administrativa humana contribui para tornar o mundo propício à dignidade da pessoa. Então, é necessário que todas as pessoas se apresentem enquanto imagem e semelhança de Deus, o que se faz enquanto matrimônio e patrimônio. São projetos de parentalidade que fomentam a vida humana, de modo que Deus seja tudo em todos, para que todos sejam um.

Quando é percebida a ausência de unidade comum na família humana, há indícios de que o sentido humano está em perspectiva de acumular o pão e não de partilhá-lo, isso inibe a essência administrativa no humano (ad-minus), e se rompe com a esponsalidade para com o Criador. Diante da esponsalidade, é possível colaborar com o reino diante das necessidades, das possibilidades e dos subsídios fazendo com que as possibilidades de uns não representem a ausência de subsídios às necessidades de outros.

\subsection{Família: necessidades, possibilidades e subsídios}

As pessoas têm capacidade de se relacionar, para tal feito, cada pessoa é convidada ao diálogo, na doação de si enquanto expressão e comunhão, bem como com a apresentação dos subsídios que tem à disposição para ser o que é. É evidente que a "relação com o universo criado e as diversas atividades que o homem dedica ao seu cuidado e transformação, quotidianamente ameaçadas pela soberba e amor desordenado de si devem ser purificadas e levadas à perfeição" (João Paulo II, 2004, $\mathrm{n}^{\circ}$ 44).

A relação e a capacidade de servir, administrando e cocriando é o que evidencia aos seres humanos, o aceitar a semelhança ao Criador. A submissão ou o efeito de se tornar submissor, inibe o direito/dever de fazer escolhas, decidir. A decisão acontece onde há 'diá-logos', isto é, um ambiente onde se propõe e não onde se impõe. Cuidar da pessoa é apresentar formas de relacionamentos com o próximo, com Deus e com a Criação e, nesta, consigo mesmo. A avareza individualiza o humano em uma economia onde a 'oferta e a procura' são os pilares, fazendo pensar que é a única alternativa em um mundo negociável.

Obcecado por possuir, o ser humano se submete à vontade dos senhores da exploração predatória. Agindo feito um predador da natureza o ser humano nega a Cristo, pois "resgatado por Cristo e tornado nova criatura no Espírito Santo, o homem pode e deve amar, com efeito, as coisas criadas por Deus. Pois de Deus as recebe: vê-as como brotando da Sua mão e como tais às respeita" (João Paulo II, 2004, nº 44).

O capitalismo/comunismo, assim como qualquer ideologia - estruturação social -, produz os sujeitos de que se precisa; assim, o capitalismo/comunismo desvirtuam sua maldade fomentando classes, rompendo com o olhar adiante, para fomentar um olhar à direita ou à esquerda. Toda a exploração predatória se dá enquanto as pessoas se digladiam na defesa de modelos/estruturas sociais e, enquanto isso acontece, o mundo segue sendo explorado predatoriamente, sem nenhuma consideração pelas gerações passadas, atuais e futuras. 
As destruições do meio-ambiente, acontecidas nos países industrializados socialistas, não são inferiores às destruições do meio-ambiente que acontecem nos países industrializados capitalistas. Pelo visto, a crise ecológica é neutra em relação ao sistema ideológico. (Moltimann, 1993, p. 52)

Imprudente é quem não constrói em esponsalidade com o Criador; Paulo VI (1968) explanou que "o amor conjugal requer nos esposos uma consciência da sua missão de 'paternidade responsável', sobre a qual hoje tanto se insiste justificadamente, e que deve também ser compreendida com exatidão" (Paulo VI, 1968, n 10). A citação é merecedora de méritos, todavia, enseja-se que a "paternidade responsável" (Paulo VI, 1968, n 10), seja compreendida como, "planejamento da parentalidade' ser pai/mãe é assumir responsabilidades, "o agir das criaturas é possibilitado através da paciência divina; a presença de Deus no mundo é o espaço livre para a liberdade das criaturas, etc” (Moltmann, 1993, p. 304).

Toda pessoa é chamada à responsabilidade pela própria vida e a de toda a humanidade, para desempenhar essa responsabilidade, função a ser exercida em família e como família. Isso não significa um agir igualitário entre pai, mãe e filhos, mas um direcionamento que promove e desenvolve o ser de cada pessoa em família e como família.

Planejamento da parentalidade é ato de amor, que deseja preservar a relação amorosa, criadora, e acolhedora, do novo ser que se possibilita a vida. Isso deve acontecer em relacionamento de amor, esperança e expectação, onde o matrimônio e o patrimônio se fazem unidade e as pessoas naquele ambiente estão aptas a colaborar com Deus na edificação do reino.

É por intermédio da concepção do ser, que deve acontecer o ato administrativo e cocriador, que "Deus atua em e através do agir das criaturas; Deus atua com e a partir do agir das criaturas; as criaturas atuam a partir das potências divinas e para dentro de um meio-ambiente divino" (Moltmann, 1993, p. 304). O humano que se desperta, na essência administrativa, diante da Graça e Providência Divina, também o faz na angústia de viver a responsabilidade que, por vezes, promove relações que se estabelecem entre o bem e o mal.

Assim, o humano vai se conhecendo diante da história, da cultura e do trabalho que desenvolve e, aos poucos, exaurindo a solidão original, entre angústias e esperanças, se põe a ouvir e a aprender a ouvir a voz de Deus. Todavia mesmo que a sabedoria humana tenha avançado sobre as questões biológicas, ainda é importante a tentativa de fomentar uma forma de viver adequadamente a vontade do Criador.

Estimulados pela voz de Deus, o ser humano atua para instigar o agir de cada pessoa e, diante da parentalidade, é possível afirmar que: "Em relação com os processos biológicos, paternidade responsável significa conhecimento e respeito pelas suas funções: a inteligência descobre, no poder de dar a vida, leis biológicas que fazem parte da pessoa" (Paulo VI, 1968, $\left.\mathrm{n}^{\mathrm{o}} 10\right)$.

Nesse sentido, também se encontra a forma de pensar o trabalho Igualmente, quando o humano se despoja das dimensões de ser família humana, e se orienta pela lógica da avareza, e sua produtividade, perde-se em uma descivilização do trabalho, e não se permite ser o ato administrativo de Deus no mundo. Toda pessoa é convidada a ser família e a cocriar e administrar o matrimônio e o patrimônio de forma a fomentar a família humana, povo/filhos de Deus.

\subsection{O trabalho e a jornada de trabalho}

É de suma importância pensar sobre a jornada de trabalho das pessoas, e sua relação com as necessidades de trabalho, para que a família humana se edifique em humanidade. É preciso "adaptar todo o processo do trabalho produtivo às necessidades da pessoa e às formas de vida; primeiramente a da doméstica, especialmente no que se refere às mães, e tendo sempre em conta o sexo e a idade" (Paulo VI, 1965, nº 67).

Fomentar sistemas de controle é, na verdade, tornar a humanidade submissa, é a regra sob a qual se constitui o 'sistema' que manda, por isso, não se pode "reduzir os colaboradores [...] à condição de simples e silenciosos executores, sem qualquer possibilidade de fazerem valer a própria experiência, completamente passivos quanto às decisões que os dirigem" 
(João XXIII, 1961, nº 92).

Quando se fala de modelos econômicos, ou mesmo das estruturas econômicas, "é demasiado frequente, mesmo em nossos dias, que os trabalhadores estão de algum modo escravizados à própria atividade. Isto não encontra justificação alguma nas pretensas leis econômicas" (Paulo VI, 1965, n 67).

O capitalismo, o comunismo, ou qualquer outro sistema de estruturação social, que, sob o preceito de mercantilização das necessidades humanas, fomenta processos em que a pessoa se torna uma peça no sistema, age contra a vontade de Deus. Não se está falando da estrutura, mas das pessoas que engendram e mantém essas estruturas.

Fala-se, pois, dos acionistas, dos gerentes, dos chefes e de todos aqueles que, mesmo vendo a negação de condições dignas para a vida humana, continuam no silêncio, preferem dar continuidade à solidão original, a propor o ser humano que é administrador e cocriador da obra de Deus. É preciso que cada pessoa possa ter a "oportunidade de desenvolver livremente as energias e capacidades que talvez pouco possam exercitar no seu trabalho profissional” (Paulo VI, 1965, nº 67).

Não se devem compreender os postos de trabalho, como prêmio aos desempregados, mas como um direito/dever que todo ser humano tem de participar do desenvolvimento participativo e compartilhado. E, por isso, é necessário que "Proporcione-se, além disso, aos trabalhadores a possibilidade de desenvolver, na execução do próprio trabalho, as suas qualidades e personalidade" (Paulo VI, 1965, n 67).

Fundamenta-se, então que, não é o que se tem, mas quantos vivem bem com o que tem sem que para isso outros tenham vivido, vivam ou venham a viver mal, dizer que há entre a Graça e a Providência de Deus a essência administrativa, é afirmar que "a providência, todavia, distingue-se da pura passividade humana, uma vez que incorpora o esforço humano para tomar parte na libertação e construção da criação" (Hefner, 1987, P. 350).

O humano não é uma peça no 'sistema'. Quando tratado dessa forma, perde-se em si mesmo, tiram-lhe a capacidade de alçar-se a ser o administrador e cocriador da Obra de Deus, torna-se evidente que cada trabalhador "ao mesmo tempo que aplica responsavelmente a esta execução o seu tempo e forças, goze, porém, todos de suficiente descanso e tempo livre para atender à vida familiar, cultural, social e religiosa" (Paulo VI, 1965, n 67),

A atividade econômica e o progresso material devem ser colocados a serviço do homem e da sociedade; se a eles nos dedicarmos com a fé, a esperança e a caridade dos discípulos de Cristo, a própria economia e o progresso podem ser transformados em lugares de salvação e de santificação. (João Paulo II, 2004, nº 326).

É possível enfatizar que a importância de elaborar teologias que substanciem a parentalidade, a economicidade e a sociabilidade da pessoa sob o mesmo contexto, se fomente a assertiva de ser administradores e cocriadores da obra de Deus. O ser humano é o ato administrativo de Deus no mundo, é a força que transforma a criação, e unge se do ato amoroso de Deus, quando, de forma livre, responsável, e consciente, faz a vontade do Criador, "Jesus sintetiza toda a Revelação pedindo ao crente enriquecer diante de Deus (cf. Lc 12,21)" (João Paulo II, 2004, nº 326).

Nesse sentido, não é cristão, favorecer um sistema que determina o quanto tempo se trabalha, e quem trabalha. É cristão sempre pensar na família humana e sua relação para com as necessidades, as possibilidades e os subsídios; “também a economia é útil para este fito, quando não trai a sua função de instrumento para o crescimento global do homem e das sociedades" (João Paulo II, 2004, no 326).

O contato entre os indivíduos está tomando um foco de avareza e possessividade, a ponto que se pode mencionar que "Nunca o gênero humano teve ao seu dispor tão grande abundância de riquezas, possibilidades e poderio econômico" (Paulo VI, 1965, n 4). Ainda que a aniquilação da família humana possa ser percebida quando se apresenta que mesmo diante de tanta riqueza, "uma imensa parte dos habitantes da terra é atormentada pela fome e pela miséria, e inúmeros são ainda os analfabetos" (Paulo VI, 1965, n 4). 
O ser humano é chamado à sensatez e à honestidade com aquilo que a natureza nos concede na graça, e deve transformar o mundo, descobrindo o sem esgotá-lo de suas energias. É necessário um caminho à unidade, onde todos sejam um para que Deus seja tudo em todos.

Percebe-se então que entre a Graça e a Providência há uma atitude humana, que, quando há a consciência de si em esponsalidade com o Criador, se possibilita que a essência administrativa eleve à vivência a "cultivar e guardar o Jardim" (Gênesis, 2,15). Não se trata de regredir, mas de evoluir, desenvolver, no entanto, é preciso despertar o humano para sua função cocriadora e administradora, quando se dá exclusividade aos filhos, em suma quando se nega a obra de Deus para amar unicamente a própria obra, nesse caso os filhos.

\subsection{Uma economia que anula a economicidade humana}

Os sistemas econômicos, de controle e adestramento, servem aos modelos produtivistas de exploração predatória, destroem a parentalidade, a sociabilidade e a economicidade humana. Em esponsalidade e "mediante o trabalho, o homem governa com Deus o mundo, juntamente com Ele é sempre seu senhor, e realiza coisas boas para si e para os outros" (João Paulo II, 2004, $\mathrm{n}^{\circ}$ 265).

O sistema de controle econômico destrói a economicidade humana; a fundo ninguém sabe ao certo o que é o sistema ao qual se está submisso, ou ainda, quem é o submissor. Quando se enfatiza a economicidade da pessoa, revela-se um ser capaz de compreender as necessidades, as possibilidades e os subsídios; as pessoas são promotoras da práxis de vida e vivência humana, estabelecendo-se no reconhecimento e desenvolvimento da dignidade da pessoa na criação.

Por isso, "a função econômica e social, que todo o homem aspira a desempenhar, exige que a atividade de cada um não se encontre submetida totalmente à vontade alheia" (João XXIII, 1961, n 92), a essência administrativa possibilita compreender a força que propulsiona a fazer, conforme o livre-arbítrio, a alteridade, e a responsabilidade, o que torna o mundo mais doméstico.

Adequadamente concebidos e geridos, os processos de globalização oferecem a possibilidade duma grande redistribuição da riqueza a nível mundial, como antes nunca tinha acontecido; se mal geridos, podem, pelo contrário, fazer crescer pobreza e desigualdade, bem como contagiar com uma crise o mundo inteiro. (Bento XVI, 2009, $\mathrm{n}^{\circ} 42$ ).

Eis que é o ser humano, a imagem e semelhança do Criador, e se torna cada vez mais visível, a referida imagem e semelhança, quando como criatura se pode perceber que em "cada trabalhador, [...], é a mão de Cristo que continua a criar e a fazer o bem" (João Paulo II, 2004, n 265). É notório que cada pessoa cuida no mundo, de um pequeno espaço no tempo, faz sempre pensando, na totalidade da obra de Deus, de modo que as possibilidades de uns, não representem a ausência aos subsídios que satisfaçam as necessidades de outros, e neste sentido:

A globalização é um fenômeno pluridimensional e polivalente, que exige ser compreendido na diversidade e unidade de todas as suas dimensões, incluindo a teológica. Isto permitirá viver e orientar a globalização da humanidade em termos de relacionamento, comunhão e partilha. (Bento XVI, 2009, nº 42).

O humano é aquele que se dá para que o mundo se ordene, segundo a vontade do Criador. Quando o humano é convidado, no mandado e no chamado, a administrar e cocriar criação, suas relações são "caracterizadas pelo respeito, pela estima e compreensão, pela colaboração leal e ativa, e pelo amor da obra comum" (João XXIII, 1961, nº 92).

Quando a humanidade está munida do desejo de desenvolvimento compartilhado e participativo, o trabalho é "considerado e vivido por todos os membros da empresa, não só como fonte de lucros, mas também como cumprimento de um dever e prestação de um serviço" (João XXIII, 1961, n 92). Aqui é necessário destacar as expressões "território ou territórios" 
(Bento XVI, 2009, $\mathrm{n}^{\circ}$ 40), enquanto o mundo em que se vive é pensar o todo, ao olhar cada uma das partes.

Quando se pensa a parte, e busca com ela dominar o todo, tudo se perde na dimensão de esponsalidade com o Criador e, por consequência, se esvai a sociabilidade, a parentalidade e a economicidade humana. Agindo, com vista só para o lucro, como uma peça manipulada, o humano perde o equilíbrio das dimensões de sociabilidade, de parentalidade e de economicidade.

Nos últimos anos, notou-se o crescimento duma classe cosmopolita de gerentes, que muitas vezes respondem só às indicações dos acionistas da empresa constituídos geralmente por fundos anônimos que estabelecem de fato as suas remunerações. (Bento XVI, 2009, nº 40)

Quando o objetivo do trabalho se transfere da edificação do ser humano e sua humanidade, para a acumulação e exploração predatória, desvincula-se da esponsalidade com o Criador, para estar submisso a um objetivo. Nesse caso, o ser humano abandona sua dimensão de economicidade, para dedicar-se à submissão de um sistema de controle econômico. Promove-se uma economia que anula a economicidade humana. O objetivo torna-se um deus, e o humano se esvai para conquistar o objeto como um trabalho, e não o trabalho como um elemento de sintonia com o criador, para edificar a si e o reino.

\subsection{Servidão à estrutura de trabalho}

É preciso estar atento às estruturas que as pessoas formam, em busca de explorar, desordenadamente, os recursos dados gratuitamente ao ser humano. É necessário estar atento, porque "também as condições degradantes de trabalho, em que os operários são tratados como meros instrumentos de lucro e não como pessoas livres e responsáveis" (Paulo VI, 1965, n² 27), e fatos como esses, aos poucos, destroem a vivência humana.

É possível, então, afirmar que, essa ação deliberada pelos governantes do Estado é profundamente infamante, agredindo a dignidade da pessoa, caluniando o ser humano, que é administrador e cocriador, tratando-o como um ser incapaz e, com isso, "ao mesmo tempo que corrompem a civilização, desonram mais aqueles que assim procedem, do que os que padecem injustamente; e que ofendem gravemente a honra devida ao Criador" (Paulo VI, 1965, n² 27).

O humano tem responsabilidade por cada pessoa, de forma que em esponsalidade com o Criador e mediante a essência administrativa é capaz de planejar a vida e vivência humana na criação, com base nos subsídios, nas necessidades e nas possibilidades.

É por ser o homo ad-minister que se pode chegar à conclusão de que "hoje, há também muitos gerentes que, através de análises clarividentes, se dão conta cada vez mais dos profundos laços que a sua empresa tem com o território ou territórios, onde opera " (Bento XVI, 2009, $\mathrm{n}^{\circ}$ 40), e onde se considera o humano, em seu próprio ser "como absoluta transcendência orientada para Deus, o 'antropocentrismo' e o 'teocentrismo' da teologia não se contradizem, mas formam rigorosamente uma única e mesma coisa " (Rahner, 1969, Pág. 1).

É fundamental, para a família humana, compreender a necessidade de sociabilidade, de economicidade e de parentalidade para com a obra de Deus, pois revela a estrutura da vivência humana, seus alicerces de funcionamento, isso tanto nas perspectivas de progresso participativo e compartilhado, quanto para a continuidade da vida humana, na plenitude de dignidade da pessoa.

O desejo de ser o Ato administrativo de Deus no mundo constituir família, um todo que administra o mundo, cocriando e administrando "a pessoa é a revelação indireta de Deus sobre a terra. Ser imagem sempre significa deixar algo aparecer e revelá-lo" (Moltmann, 1993, Pág. 317).

A administração, aqui é uma palavra que remete ao homo ad-minister, ser em esponsalidade com o Criador, elevado a 
compreender quais são as atividades que possibilitam viver em conjugalidade promovendo o equilíbrio entre as dimensões de economicidade, de sociabilidade e de parentalidade.

A família que, se origina na consanguinidade, guia-se pela vontade do Criador, propulsando o amor para a sociabilidade e, assim, guiado pelo bom, belo e verdadeiro, edifica o reino que é possível, segundo as necessidades, as possibilidades e os subsídios. O matrimônio é, então, esponsalidade com o Criador que se demonstra em ato ao cônjuge e, por isso, "O matrimônio não é, portanto, fruto do acaso, ou produto de forças naturais inconscientes: é uma instituição sapiente do Criador, para realizar na humanidade o seu desígnio de amor" (Paulo VI, 1968, nº 8).

Se houvesse a possibilidade de escolher uma palavra no 'dicionário cristão' escolher-se-ia a palavra 'Esperança'. A esperança é constitutiva da ação necessária na realização do que é esperançado e, assim, se insere a criação do ser humano no Reino esperançado por Deus, no qual o ser humano é o administrador e cocriador.

\section{Considerações Finais}

O des-envolvimento participativo e compartilhado, precisa ser pensado enquanto reino, o jeito de reinar, para que os frutos do des-envolvimento não sinalizem para as riquezas de uns e pobrezas de outros, mas que sinalizem para a fonte de fraternidade humana. Neste sentido, o des-envolvimento, não pode ser só econômico, no sentido de se gerar riquezas - cifras monetárias. O des-envolvimento precisa acontecer sob a perspectiva da pessoa, de todo o humano e do humano todo.

É preciso se perceber a importância de que, cada pessoa se compreenda, enquanto dom para a vida humana e, assim mediante as dimensões de sociabilidade, de economicidade e de parentalidade toda pessoa que é, sinta-se, chamada a administrar a obra de Deus. É preciso, ainda, enfatizar que o objetivo do des-envolvimento não está para a construção de sistemas de controle, mas para a formação da consciência de pessoa.

Quando o foco é o des-envolvimento de sistemas de controle, a estruturação Estatal, termina por fomentar sistemas econômicos que anulam a economicidade da pessoa, sistemas sociais que destroem as relações entre os seres humanos, bem como quando, se pensa a família sobre a perspectiva de familismo, se destrói a liberdade de se doar ao projeto de amor de Deus. Neste sentido, o que se busca é a formação da consciência de pessoa - a verdade liberta e não fomenta estruturas Estatais.

É preciso que se pense as famílias, a partir das pessoas nas famílias, suas necessidades, suas possibilidades e seus subsídios, de forma que a vida e vivência humana chegue à percepção de que não é o que se tem, é, quantos vivem bem com o que se tem, sem que para isso outros tenham vivido, vivam, ou venham a viver mal. Estes elementos precisam ser pensados, prudentemente, em cada lar, dialogando com respeito e serenidade e que desta forma, a pessoa não seja para servir à estrutura de trabalho, mas seja, a pessoa que Deus criou, em livre-arbítrio, para administrar e cocriar a obra de Deus.

\section{Referências}

Bento XVI. Caritas In Veritate. Roma: Libreria Editrice Vaticana, 2009. http://w2.vatican.va/content/benedictxvi/pt/encyclicals/documents/hf_benxvi_enc_20090629_caritas-in-veritate.html.

Bíblia. Português. Bíblia de Jerusalém. Nova edição revisada e ampliada: Paulus, $8^{\mathrm{a}}$ impressão, 2012.

Bruner, J. Atos de significação. (2 ${ }^{\mathrm{a}}$. ed.) Trad. Sandra Costa. São Paulo: Artmed, 2002.

Clandinin, D. J., \& Conelly, F. M. Pesquisa narrativa: experiências e história na pesquisa qualitativa. Tradução: Grupo de Pesquisa Narrativa e Educação de Professores ILEEL/UFU: EDUFU, 2011.

Francisco. Amoris laetitia. Roma: Libreria Editrice Vaticana, 2016. http://w2.vatican.va/content/francesco/pt/apost_exhortations/documents/papafrancesco_esortazione-ap_20160319_amoris-laetitia.html.

Francisco. Laudato Si'. Roma: Libreria Editrice Vaticana, 2015. http://w2.vatican.va/content/francesco/pt/encyclicals/documents/papafrancesco_20150524_enciclica-laudato-si.html.

Gênesis. In: Bíblia de Jerusalém. Nova edição revisada e ampliada: Paulus, 2012. 
Research, Society and Development, v. 10, n. 15, e535101523371, 2021

(CC BY 4.0) | ISSN 2525-3409 | DOI: http://dx.doi.org/10.33448/rsd-v10i15.23371

Hefner, P. J. A Criação. In: Braaten, Carl E., Jenson, R. W. (editores). Dogmática Cristã. Sinodal, 1987. p. 273-358.

João Paulo II. Compêndio da Doutrina Social da Igreja: Libreria Editrice Vaticana, 2004. http://www.vatican.va/roman_curia/pontifical_councils/justpeace/documents/rc_pc_justpeace_doc_20060526_compendio-dott-soc_po.html.

João Paulo II. Evangelium vitae. Libreria Editrice Vaticana, 1995. http://w2.vatican.va/content/paul-vi/pt/encyclicals/documents/hf_pvi_enc_25071968_humanae-vitae.html.

João Paulo II. Familiaris Consortio. Libreria Editrice Vaticana, 1981. http://w2.vatican.va/content/john-paul-ii/pt/apost_exhortations/documents/hf_jpii_exh_19811122_familiaris-consortio.html.

João XXIII. Mater et magistra. Libreria Editrice Vaticana, 1961. http://w2.vatican.va/content/john-xxiii/pt/encyclicals/documents/hf_jxxiii_enc_15051961_mater.html. (João XXIII, 1961, nº

Moltimann, J. Deus na criação: doutrina ecológica da criação. Tradução: Haroldo R., Ivoni R. R. Vozes, 1993.

Paulo VI. Gaudium et Spes. Libreria Editrice Vaticana, 1965. http://www.vatican.va/archive/hist_councils/ii_vatican_council/documents/vatii_const_19651207_gaudium-et-spes_po.html. (Paulo VI, 1965, nº

Paulo VI. Humanae Vitae. Libreria Editrice Vaticana, 1968. http://w2.vatican.va/content/paul-vi/pt/encyclicals/documents/hf_p-vi_enc_25071968_humanaevitae.html.

Paulo VI. Populorum Progressio. Libreria Editrice Vaticana, 1967. http://w2.vatican.va/content/paul-vi/pt/encyclicals/documents/hf_pvi_enc_26031967_populorum.html.

Rahner, Karl. Teologia e Antropologia. São Paulo, SP: Edições Paulinas, 1969.

Sanches, M. A. Reprodução Assistida e Bioética - Metaparentalidade. (1ª. ed.): Ave Maria, 2013. v. 1. 218p. 